\title{
Body integrity identity disorder crosses culture: case reports in the Japanese and Chinese literature
}

This article was published in the following Dove Press journal:

Neuropsychiatric Disease and Treatment

16 June 2016

Number of times this article has been viewed

\section{Rianne M Blom' \\ Nienke C Vulink' \\ Sija J van der Wal' \\ Takashi Nakamae ${ }^{\text {l-3 }}$ \\ Zhonglin Tan ${ }^{1,4}$ \\ Eske M Derks' \\ Damiaan Denys ${ }^{1,5}$}

'Department of Psychiatry, Academic Medical Center, University of Amsterdam, Amsterdam, the Netherlands; ${ }^{2}$ Department of Psychiatry, Graduate School of Medical Science, Kyoto Prefectural University of Medicine, ${ }^{3}$ Department of Neural Computation for DecisionMaking, ATR Brain Information

Communication Research Laboratory Group, Kyoto, Japan; ${ }^{4}$ Department of Psychiatry, Hangzhou Mental Health Center, Hangzhou, People's Republic of China; ${ }^{5}$ Netherlands Institute for Neuroscience, Royal Netherlands Academy of Arts and Sciences, Amsterdam, the Netherlands
Correspondence: Rianne M Blom Department of Psychiatry, Academic Medical Center, University of

Amsterdam, PA.I-I5I, Meibergdreef 5, II05 AZ Amsterdam, the Netherlands Tel +3I 208913600

$\mathrm{Fax}+3|2089| 3898$

Email riannemb@gmail.com

\begin{abstract}
Body integrity identity disorder (BIID) is a condition in which people do not perceive a part of their body as their own, which results in a strong desire for amputation or paralyzation. The disorder is likely to be congenital due to its very early onset. The English literature describes only Western patients with BIID, suggesting that the disorder might be merely prevalent in the West. To scrutinize this assumption, and to extend our knowledge of the etiology of BIID, it is important to trace cases with BIID in non-Western populations. Our objective was to review Chinese and Japanese literature on BIID to learn about its presence in populations with a different genetic background. A systematic literature search was performed in databases containing Japanese and Chinese research, published in the respective languages. Five Japanese articles of BIID were identified which described two cases of BIID, whereas in the Chinese databases only BIID-related conditions were found. This article reports some preliminary evidence that BIID is also present in non-Western countries. However, making general statements about the biological background of the disorder is hampered by the extremely low number of cases found. This low number possibly resulted from the extreme secrecy associated with the disorder, perhaps even more so in Asian countries.
\end{abstract}

Keywords: amputation, cross-cultural comparison, apotemnophilia, treatment, phenomenology, genetics

\section{Introduction}

Body integrity identity disorder (BIID) involves the desire to have a limb amputated or to be paralyzed in order to correct the perceived mismatch between a person's sense of body identity and his or her actual anatomy. ${ }^{1-3}$ The etiology and prevalence of the disorder are poorly studied. Of the 100-200 cases described in the literature, most are males of Caucasian origin. ${ }^{1,4,5}$ To extend the limited knowledge of BIID, in this report, we try to retrieve cases with BIID in the Asian literature.

Originally, the disorder was seen as a paraphilia. According to this view, the comparison of an amputation stump with a phallus would lead to sexual arousal. The disorder was named apotemnophilia, which is ancient Greek for "love to cut away". 6,7 In the beginning of this century, the incongruence between one's experienced and assigned body thus became paramount to the sexual desire. Parallels - the "not feeling well in one's body" - were made with gender dysphoria, and the condition was named "body integrity identity disorder". 1,5,8 To date, an alternative, neurobiological hypothesis about the etiology of this rare condition has been proposed. It has been suggested that the feeling of body ownership is mediated by a frontal parietal network, including multisensory integration areas, such as the parietal cortex and premotor cortex, as well as the insula. ${ }^{9,10}$ Recently, structural and functional abnormalities in this network have been reported in patients with BIID. Currently, some neuroscientists prefer to 
refer to the condition as xenomelia instead of BIID, as it is a more neutral term. ${ }^{11,12}$

Generalization of BIID features and prevalence estimations are hampered by the absence of epidemiological studies. Drawing from the 100-200 patients with BIID described in case reports and small cohorts, we have learned that $\sim 80 \%$ of the patients with BIID are male and most of the patients have received higher education. ${ }^{1,4,5,13}$ Besides their BIID, patients are otherwise healthy individuals with no major psychiatric comorbidity. ${ }^{1,5,14}$ Nevertheless, they experience a high disease burden and there is no pharmacological or otherwise therapeutic treatment available. ${ }^{1,13}$ Patients with BIID recognize the bizarre character of their wish to amputate or paralyze body parts, which results in being vigilant and reserved in sharing their feelings with others. ${ }^{1,14}$

Historically, leg amputation is the most common variant of BIID, but other desired disabilities such as arm amputation, paralyzation, or even blindness are proposed to be a form of BIID as well. ${ }^{2,3}$ Unlike in factious disorder, patients with BIID do not aim for disability in order to gain any variety of benefits (ie, attention, nurturance, leniency, and profit) other than feeling at ease with their own body. ${ }^{1,5}$ There is no motor or sensory dysfunction of the affected body part and there is no pain, disease, conversion, psychosis, or imagined ugliness that could explain the desirability of amputation. ${ }^{1,5,15}$ In some reported BIID samples, BIID is associated with a higher prevalence of homosexuality (of $\sim 40 \%$ ) and is related to gender dysphoria. ${ }^{1,2,5,16}$ However, these prevalences could be an overestimation due to selection biases of the reported samples. ${ }^{1,5}$ The onset of BIID lies in the early childhood and the main motivation for preferred body modification is that the particular body part feels supernumerary. ${ }^{1,5}$ Although familial BIID has not yet been described, it has been hypothesized that there might be a genetic background. ${ }^{1,17}$ The main rationale for suggesting this genetic background is that the disorder is likely to be congenital. Most patients with BIID have feelings of disownership from as long as they can remember, and those feelings are fixed and do not seem to be malleable by any form of therapy. ${ }^{1,10,17}$ It is uncertain whether the absence of reported familial cases results from their actual nonexistence or because many patients with BIID do not share their bizarre wish with their loved ones. ${ }^{1}$

To the best of our knowledge, only cases in Western countries have thus far been described. Internet forums have even seen speculations that individuals with BIID might share a German ancestry. ${ }^{18}$ However, this has not been confirmed. We aimed to investigate whether reports exist on cases with BIID in Asian countries, in order to gain more knowledge of the origin of this rare condition. More specifically, our aim has been to learn whether BIID is influenced by cultural factors, to learn about its presence in populations with slightly different genetic backgrounds, and to compare phenotypic characteristics across different populations. Therefore, we performed a literature search in local medical databases in the People's Republic of China and Japan in an attempt to find patients with BIID with an Asian background.

\section{Methods}

\section{Literature search}

To find the Japanese literature on BIID, a systematic search was performed in May 2013 in Ichushi Web, which is the largest Japanese database of medical literature. First, publications were retrieved by a computerized search of databases using the keywords 身体完全同一性障害 (身体 shintai, body or physical; 完全 kanzen, integrity, perfect or complete; 同一性 douitsusei, identity; 障害 syougai, disorder). Five articles were found and all of them described patients with BIID. After reading the full text of the articles, it became apparent that some of them overlapped. Two cases described the same patient, doubly reported by some plastic surgeons and a dermatologist who both treated the same patient. The other three articles described another case. This case is reported by a group of plastic surgeons in three different articles (a conference report, a regular case report, and a review). We thus found two original cases. Second, to retrieve more articles, the search was extended using BIID-related keywords: “四肢 limbs and 同一性障害 identity disorder”, “肢切断術 amputation and 自己 self”, “四肢 limbs and 自傷 self-injury”, “四肢 limbs and 偽麻痺 pseudo-paralysis”, “四肢切断愛者 acrotomophilia”, “四肢切断熱望者 apotemnophilia”, “四肢 limbs and 切断者愛好 devotee”, “四肢 limbs and 偽装 pretender”, “四肢 limbs and 切望 wannabe”. The extended search using BIID-related keywords revealed no new BIID articles, not even BIID-related reports.

Furthermore, to discover Chinese articles about BIID, a systematic literature search was performed in the three main databases of Chinese articles including China Academic Journals Full-text Database (1984-2013), Wanfang Database (1998-2013), and VIP Database (1989-2013). Initially, a search was performed using “躯体完整性认同障碍” or “截肢者认同障碍”(BIID), and“肢体” and“认同障碍”(limbs and identity disorder). Through this search, no BIID articles were found. Later, more keywords from Western BIID articles were retrieved. These terms were used in a second search and included the following: “自行截肢” (self-amputation); “截肢” (amputation); “肢体自残” (limbs self-injury); 
“自残”(self-injury); “假性㿈疾” (pseudo-paralysis); “慕残” or “慕残者” (acrotomophilia, devotee); “扮残” or “扮残者” (apotemnophilia, pretender); “自残者” (wannabe). In this second, extended search, some articles were retrieved. After reading the full texts, it turned out that the cases found mainly concerned self-injury, automutilation, or amputation for other reasons. For example, there was a report of a man who amputated his arm after being crushed by a boiler for 3 days. Other articles described a man who cut his left palm and a woman who broke both her legs during a car accident. However, in these cases, it was assumed that these measures were taken in order to claim money from medical insurance companies. In the end, therefore, we retrieved two cases of possible BIID in the People's Republic of China.

\section{Results}

The two cases from the articles found in the Japanese literature were translated from Japanese to English by a bilingual psychiatrist and are summarized in the following paragraphs.

Case 1 is the report of a young female patient seen by the article's authors (a dermatologist, a plastic surgeon, and a consulting psychiatrist) after mutilation of her left leg. ${ }^{19}$ At the age of 16 years, she was diagnosed with major depressive and self-mutilating behavior such as wrist cutting and cigarette burning, for which she took antidepressants. She had a "feeling of wrongness" relating to her left leg, and always had the feeling that she needed to cut it off herself. At the age of 18 years, she laid her leg in dry ice for several hours, after which a skin graft operation was necessary. The operation wound never healed completely, and the woman continued harming the unhealed wound. At the age of 21 years, she developed osteomyelitis, which resulted in an operative amputation of her left leg to the level above her knee. "I wanted to cut my leg from the beginning. I have a leg. That is the problem", she argued. No official diagnosis of BIID had been made.

The second case is a 21-year-old man with a request for the amputation of his left leg after putting it in dry ice for 6 hours. ${ }^{20}$ The case is reported by the plastic surgeons who treated the patient. This patient had been experiencing a "feeling of wrongness", relating to his left leg since he was a child; he adored Captain Hook and other amputees. Later on he was diagnosed with BIID by a consulting psychiatrist. The plastic surgeons opposed his request and performed reconstructive amputations, enabling him to walk, although with some difficulties. He still had a feeling of wrongness toward his leg, but he did not want to perform self-mutilation anymore. He was somehow satisfied because he felt his state was close to what he initially had in mind.

From the Chinese literature, two cases of possible BIID were retrieved. The first one was a letter from a psychologist who helped a woman on an Internet forum. ${ }^{21}$ This 28 -yearold woman had pretended from childhood on to be disabled. She used medical supplies to enhance credibility. This pretending excited her. Being disabled granted her attention from others that she had always missed from her parents. The second letter is from a patient who asked why he is so obsessed with other people with disabilities. ${ }^{22}$ Seeing other amputees, especially girls, excited him and made him happy. Afterward he felt remorse. He could not understand why he was so obsessed with disabilities.

\section{Discussion}

This article describes four BIID-related cases in the People's Republic of China and Japan. ${ }^{19-22}$ We hypothesize that the patient in the first Japanese case suffered from BIID as she claimed her leg to be superfluous; her thoughts about her leg not being her own were very persistent and pharmacological therapy did not influence these BIID thoughts. ${ }^{19}$ One might argue that burning her leg with dry ice can be seen as selfinjurious behavior, just as the patient performed wrist cutting in the past. However the wrist cutting seems more of an impulse control disorder in contrast to the mutilation of the leg, which had been meticulously planned. The second case from Japan reports explicit BIID features: the early onset, the feeling of overcompleteness, and the perseverance of this thought. ${ }^{20}$ The patient's adoration of Captain Hook may be either jealousy ("that is how I would like to be") or a form of sexual attraction toward other amputees, better known as acrotomophilia. ${ }^{23}$ Such feelings of both jealousy and sexual attraction have been described in BIID. ${ }^{2,16}$

The Chinese cases are less clear. ${ }^{21,22}$ Patients faking accidents in order to get medical insurance fees are often described in the literature and these behaviors are known as simulation. However, due to the secrecy and shame that often accompanies BIID, some patients create accidents in order to get their leg amputated, without letting their relatives know the true reason of the accident. ${ }^{24,25}$ The woman who pretended to be disabled is not likely to suffer from BIID. Although pretending is a common symptom in BIID, her motivation to pretend was rooted in the attention it drew and not "to feel complete in her own body". ${ }^{1,5,21}$ The patient who mentioned getting excited by seeing other amputees might be suffering from acrotomophilia. This condition can exist alongside BIID, although it may exist independently as well., 5,16,22 
To summarize, after a search in the Japanese literature one straightforward and one likely case with BIID were found, both describing the amputation variant of BIID. In the Chinese literature, only BIID-related conditions are described. The reports do not give sufficient information to reach any conclusions about anything concerning the background of the symptoms. The fact that only few reports were found may have several causes. It is known that patients with BIID have difficulties in sharing their BIIDrelated feelings with people in their environment, because they are aware of the peculiarity of these feelings. In one of our other studies including 54 patients with BIID, just half of the patients shared their bizarre thoughts with spouses, friends, or family. ${ }^{1}$ All the patients examined in this other study were from Western countries. Chinese and Japanese cultures are known to be more reserved when it comes to self-disclosure. ${ }^{26,27}$ Therefore, letting others in on BIID might be even more difficult. Likewise, in Japan and the People's Republic of China, it is assumed to be more difficult to live with an identity that most people would judge as unusual. For example, people with a homosexual identity or feelings of gender dysphoria are less publicly accepted than in some Western countries. ${ }^{28}$ Therefore, it might be more difficult for people with BIID to "come out of the closet". Moreover, as literature is sparse, medical professionals might not be familiar with this condition. Therefore, individuals with BIID in these countries could easily be wrongly diagnosed. This might also explain why no paraplegia cases with BIID have been reported, as this specific type has only recently been described in the literature.

This paper reports some preliminary evidence of BIID's presence in non-western countries. The extremely low number of cases found hampers making general statements about the biological background of the disorder. However, BIID is a rare and an extremely secretive condition, perhaps it is even more so in Asian countries, which poses a major obstacle estimating its prevalence. We hypothesize that the cases found are likely to be an underestimation of the presence of the disorder. On the other hand, this might be a reflection of the extreme rarity of the disorder in the People's Republic of China and Japan. Further research is needed to reveal the prevalence and phenomenological features of BIID in Asian and other non-Western countries. We hope this article would encourage the submission and publication of additional Chinese and Japanese articles on BIID and improve the screening of BIID in those countries. This should create more awareness of the existence of BIID among local health-care workers. Awareness could subsequently lead to acknowledgment and respect for this unusual desire, which is always a first and crucial step in the treatment of patients with BIID.

\section{Acknowledgment}

We kindly thank E de Lange for carefully correcting the language errors.

\section{Author contributions}

RMB and DD conceived and designed the manuscript. TN and ZT performed the literature search. All authors contributed toward data analysis, drafting and critically revising the paper, and agree to be accountable for all aspects of the work.

\section{Disclosure}

The authors report no conflicts of interest in this work.

\section{References}

1. Blom RM, Hennekam RC, Denys D. Body integrity identity disorder. PLoS One. 2012;7(4):e34702.

2. First MB, Fisher CE. Body integrity identity disorder: the persistent desire to acquire a physical disability. Psychopathology. 2012;45(1):3-14.

3. Giummarra MJ, Bradshaw JL, Hilti LM, Nicholls MER, Brugger P. Paralyzed by desire: a new type of body integrity identity disorder. Cogn Behav Neurol. 2012;25(1):34-41.

4. Bou Khalil R, Richa S. Apotemnophilia or body integrity identity disorder: a case report review. Int J Low Extrem Wounds. 2012;11(4): 313-319.

5. First MB. Desire for amputation of a limb: paraphilia, psychosis, or a new type of identity disorder. Psychol Med. 2005;35(6):919-928.

6. Money J, Jobaris R, Furth G. Apotemnophilia: two cases of self-demand amputations as paraphilia. J Sex Res. 1977;13(2):115-125.

7. Dua A. Apotemnophilia: ethical considerations of amputating a healthy limb. J Med Ethics. 2010;36(2):75-78.

8. Brugger P, Lenggenhager B. The bodily self and its disorders: neurological, psychological and social aspects. Curr Opin Neurol. 2014; 27(6):644-652.

9. van Dijk MT, van Wingen GA, Van LA, et al. Neural basis of limb ownership in individuals with body integrity identity disorder. PLoS One. 2013;8(8):e72212.

10. Hilti LM, Hanggi J, Vitacco DA, et al. The desire for healthy limb amputation: structural brain correlates and clinical features of xenomelia. Brain. 2013;136(pt 1):318-329.

11. McGeoch PD, Brang D, Song T, Lee RR, Huang M, Ramachandran VS. Xenomelia: a new right parietal lobe syndrome. J Neurol Neurosurg Psychiatry. 2011;82(12):1314-1319.

12. Palla A, Hilti LM. An impaired spatial-temporal integration of touch in xenomelia (body integrity identity disorder). Spat Cogn Comput. 2012; 1072954(2-3):96-110.

13. Sedda A, Bottini G. Apotemnophilia, body integrity identity disorder or xenomelia? Psychiatric and neurologic etiologies face each other. Neuropsychiatr Dis Treat. 2014;10:1255-1265.

14. Sedda A. Body integrity identity disorder: from a psychological to a neurological syndrome. Neuropsychol Rev. 2011;21(4):334-336.

15. Kasten E, Spithaler F. Body integrity identity disorder: personality profiles and investigation of motives. In: Stirn A, Thiel A, Oddo E, editors. Body Integrity Identity Disorder. Lengerich: Papst Science Publishers; 2009:20-40.

16. De PH, De Preester H. Merleau-Ponty's sexual schema and the sexual component of body integrity identity disorder. Med Health Care Philos. 2013;16(2):171-184. 
17. Ramachandran VS, McGeoch P. Can vestibular caloric stimulation be used to treat apotemnophilia? Med Hypotheses. 2007;69(2):250-252.

18. Transabled.org [homepage on the Internet]. Available from: http:// transabled.org/. Accessed January 12, 2013.

19. Mizutani T, Sasaki S, Sadamoto Y. [Lower leg frostbite due to dry ice]. Pract Dermatol. 2011;33(6):633-636. Japanese.

20. Horiguchi M, Hayashi R, Furumoto M, Shimizu A, Komuro H. [Heel frostbite due to self-mutilation in a patient with body integrity identity disorder]. J Jpn Soc Plast Reconstr Surg. 2011;31(3):185-189. Japanese.

21. Qing D. [Focus on DPW's psychological need]. Mass Psychol China. 2006;12:42-43. Chinese.

22. Yuan H. [Why am I infatuated with disabilities?] Fam Nurse China. 2004;11:54. Chinese.

23. Money J, Simcoe KW. Acrotomophilia, sex and disability: new concepts and case report. Sex Disabil. 1984;7(1-2):43-50.
24. Blom RM, Braam AW, de Boer-Kreeft N, Sonnen MPAM. Blijvende opluchting na beenamputatie bij body integrity identity disorder. [Body integrity identity disorder, relief after amputation]. Tijdschr Psychiatr. 2014;56(1):54-57. Dutch.

25. Blom RM, Hennekam RCM. Amputatiewens bij 'body integrity identity disorder. [Desire for amputation in body integrity identity disorder]. Ned Tijdschr Geneeskd. 2014;158:A7146. Dutch.

26. Chen G-M. Differences in self-disclosure patterns among Americans versus Chinese: a comparative study. J Cross Cult Psychol. 1995;26(1): 84-91.

27. Kito M. Self-disclosure in romantic relationships and friendships among American and Japanese college students. J Soc Psychol. 2005; 145(2):127-140.

28. Guo Y, Li X, Liu Y, Jiang S, Tu X. Disclosure of same-sex behavior by young Chinese migrant men: context and correlates. Psychol Health Med. 2014;19(2):190-200.
Neuropsychiatric Disease and Treatment

\section{Publish your work in this journal}

Neuropsychiatric Disease and Treatment is an international, peerreviewed journal of clinical therapeutics and pharmacology focusing on concise rapid reporting of clinical or pre-clinical studies on a range of neuropsychiatric and neurological disorders. This journal is indexed on PubMed Central, the 'PsycINFO' database and CAS,

\section{Dovepress}

and is the official journal of The International Neuropsychiatric Association (INA). The manuscript management system is completely online and includes a very quick and fair peer-review system, which is all easy to use. Visit http://www.dovepress.com/testimonials.php to read real quotes from published authors.

Submit your manuscript here: http://www.dovepress.com/neuropsychiatric-disease-and-treatment-journal 